\title{
Article \\ Development of COVID-19 Case in District and City of Jambi Province with Exponential Smoothing Methode
}

Article Info

Article history:

Received September 22, 2020 Revised September 28, 2020

Accepted September 28, 2020

Published September 30, 2020

Keywords :

covid-19, forcest, exponensial smoothing

\section{Sherli Yurinanda ${ }^{1 *}$, Cut Multahadah ${ }^{1}$, Reni Aryani $^{2}$}

${ }^{1}$ Department of Mathematics, Faculty of Science and Technology, Universitas Jambi, Jambi, Indonesia

${ }^{2}$ Information Systems Study Program, Faculty Of Science And Technology, Universitas Jambi, Jambi, Indonesia

\begin{abstract}
Jambi Province is one of the province in western Indonesia, which was affected by COVID-19 in March and until mid-September the number confirmed positive reached 345 people. Until now COVID-19 has become a pandemic.Based on this data, it is necessary to predict the number of COVID-19 in Jambi Province, including every district in Jambi city. Forecasting activities are predicting what will happen in the future based on accurate data in the past. if the time series contains a trend, seasonal influence or trend and seasonal influence at the same time, then the simple average cannot describe the data pattern so there is an exponential smoothing method which is used as an alternative for forecasting future periods. Double exponential smoothing: The Holt twoparameter method determines the value of the trend with a tang parameter different from the parameter used in the original series. The principle of forecasting using multiple exponential smoothing: The Holt two-parameter method uses two smoothing constants with values between 0 and 1 . Based on the results of forecasting using the double exponential smoothing by Holt method, it can be seen that the number of confirmed cases of Covid-19 in each region in Jambi Province continues to increase. This case is estimated to increase to 352 people in mid-October.
\end{abstract}

This is an open acces article under the $\underline{C C-B Y}$ license.

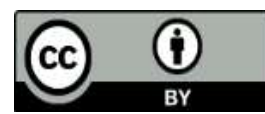

This is an open access article distributed under the Creative Commons 4.0 Attribution License, which permits unrestricted use, distribution, and reproduction in any medium, provided the original work is properly cited. (C2020 by author. 


\section{Introduction}

At the end of 2019, cases of mysterious pneumonia were first reported in Wuhan, Hubei Province these cases increased rapidly, marked by the reported number of 44 cases [13]. In less than a month, the disease has spread to various other provinces in China, Thailand, Japan and South Korea, including Indonesia. Until now it is known as COVID-19 and has become a pandemic. Based on data from the Task Force for the Acceleration of Handling COVID-19 (BNPB) on September 15, 2020 the number of positive corona cases reached 225,030 people with the death rate for COVID-19 patients are 8,965 people[1]. Because of that, the disease should be watched out for because of the transmission is relatively fast and there is no definitive therapy.

Jambi Province is one of the province in western Indonesia, which was affected by COVID-19 in March and until mid-September the number confirmed positive reached 345 people [3]. Based on this data, it is necessary to predict the number of COVID-19 in Jambi Province, including every district in Jambi city. This is important to do as a suggestion to the government whether in the next month the increase in cases will increase by a higher rate. COVID-19 is a new disease so prevention efforts are still limited [2-7]. Prevention keys include insulating transmission chain disconnection, early detection, and basic protection (12). Because of that, it's a must to forecasting the the development of COVID-19 case in district and city of Jambi Province.

Forecasting is a time lag between awareness of future events or needs with the event itself where a prediction is needed when an event will occur or arise so that appropriate action can be taken to overcome it. So forecasting activities are predicting what will happen in the future based on accurate data in the past. Formal quantitative forecasting based on statistical principles using horizontal, seasonal and trend extrapolations with the principle of using a systematic approach that minimizes forecast errors[11].

Makridakis states that if a periodic series is generated by a constant process containing random errors, then the simple average can be used as a forecast for future periods. However, if the time series contains a trend, seasonal influence or trend and seasonal influence at the same time, then the simple average cannot describe the data pattern so there is an expoential smoothing method which is used as an alternative for forecasting future periods. Double exponential smoothing: The Holt twoparameter method determines the value of the trend with a tang parameter different from the parameter used in the original series. The principle of forecasting using multiple exponential smoothing: The Holt two-parameter method uses two smoothing constants with values between 0 and $1[11]$.

The relevant research conducted by Harini is the identification of Covid-19 Cases in Indonesia with the double exponential smoothing method. The Double Exponential Smoothing method is one method that can be used to optimize the estimation of the ARIMA model with smoothing parameters $\alpha$. The results of his research show that the PACF, ACF and ARIMA model parameter estimates in the Covid-19 case in Indonesia follow the modelARIMA $(0,1,1)[12]$. Whereas in this study using double exponential smoothing: Holt's two-parameter method to predict the number of positive cases of Covid-19 in 11 districts in Jambi Province, namely Sungai Penuh City, Kerinci, Jambi City, Muaro Jambi, Batanghari, TanjungJabung Barat, TanjungJabungTimur ,Tebo, Bungo, Merangin and Sarolangun.

\section{Review Literature}

\subsection{Exponential Smoothing}

A group of methods that show the weighting decreases exponentially with the value of the older observation is called the exponential smoothing procedure. The exponential smoothing method 
consists of single, multiple, and more complex methods. All of them have the same properties, namely the newer value is given a relatively greater weight than the older observed value. The weights applied to the observed values are a byproduct of the particular MA (moving average) system being taken. But in exponential smoothing, there are one or more smoothing parameters that are specified explicitly, and the result of this selection determines the weighting value applied to the observed value[11].

The equation used in the single exponential smoothing method can be written in the following equation:

Where

$$
S_{t+1}=\alpha X_{t}+(1-\alpha) S_{t}
$$

$S_{t+1}:$ smoothing for the period $t+1$

$X_{t} \quad$ : actual value in period to $t$

$F_{t} \quad$ : forecasting in period to $t$

$\alpha$ : parameter / weight / smoothing constant $(0<\alpha<1)$

If we look at the formula, it seems as if the forecast only pays attention to the last observation data, but actually the data from previous years have also been taken into account. The implications of the single exponential smoothing method can be extended by substituting $S_{t}$ with the following components:

$$
\begin{gathered}
S_{t+1}=\alpha X_{t}+(1-\alpha) S_{t} \\
S_{t}=\alpha X_{t}+(1-\alpha) S_{t-1} \\
S_{t+1}=\alpha X_{t}+(1-\alpha)\left\{\alpha X_{t-1}+(1-\alpha) S_{t-1}\right\} \\
S_{t+1}=\alpha X_{t}+\alpha(1-\alpha) X_{t-1}+(1-\alpha)^{2} S_{t-1}
\end{gathered}
$$

If this substitution process is repeated by replacing $S_{t-1}$ with its components, $S_{t-2}$ with its components and so on, then the result of the substitution of the above equation becomes:

$$
\begin{gathered}
S_{t+1}=\alpha X_{t}+\alpha(1-\alpha) S_{t} X_{t-1}+\alpha(1-\alpha)^{2} X_{t-2}+\alpha(1-\alpha)^{3} X_{t-3}+\alpha(1-\alpha)^{4} X_{t-4}+\cdots+ \\
\alpha(1-\alpha)^{N-1} X_{t-(N-1)}
\end{gathered}
$$

From theequation above, it is known that the weight used for each value that has occurred in the past increases exponentially and this is what is called the exponential smoothing method. It should be noted that the objective of this method is to minimize the mean square error. It can be rewritten as follows :

$$
\begin{gathered}
S_{t+1}=\alpha X_{t}+(1-\alpha) S_{t} \\
=S_{t}+\alpha\left(X_{t}-S_{t}\right)
\end{gathered}
$$

If $X_{t}-S_{t}$ replaced with $e_{t}$ then the equation becomes:

$$
S_{t+1}=S_{t}+\alpha\left(e_{t}\right)
$$

with $e_{t} \mathrm{~s}$ the forecast error (true value minus the forecast) for period $t$ [11].

The main advantages of using the smoothing method are its simplicity and low cost. There is little doubt whether better precision can always be achieved using autoregressive methods or more sophisticated moving average patterns. However, if a forecast for thousands of items is required, as in most cases of inventory, the smoothing method is often the only method that can be used. If the data series is stationary, then a single exponential smoothing with an adaptive response rate is often preferred over a single exponential smoothing method, because the single exponential smoothing method requires determination $\alpha$ in such a way as to minimize MSE 
(Mean Squared Error). More important things, $\alpha$ optimal changes will change when there is a basic change in the data pattern. If not, there will be a risk of severe forecasting errors.

\subsection{Double Exponential Smoothing}

\section{a. Initialization}

Determining the initialization of the initial value has an important role in forecasting using the exponential smoothing method. This can be seen in the single exponential smoothing equation. For example, to calculate the smoothing period ahead

When $t=1$, the equation above become :

$$
S_{t+1}=\alpha X_{t}+(1-\alpha) S_{t}
$$

To get value of $S_{2}, S_{1}$ must be known in advancevalue $S_{1}$

$$
S_{2}=\alpha X_{1}+(1-\alpha) S_{1}
$$

$$
S_{1}=\alpha X_{0}+(1-\alpha) S_{0}
$$

However, the values for $X_{0}$ and $S_{0}$ are missing. Likewise, the value of $S_{1}$ must be known to calculate the value of $S_{2}$. However, this value is not obtained from existing data. Therefore we need a way to determine the value of $S_{1}$. (initial value). There are many ways to determine the initial value, here are some ways to determine the initial value for several types of exponential smoothing methods[13]:

a. Single exponential smoothing method

$S_{1}=X_{1}$
b. Brown's double exponential smoothing method (one-parameter linear)

$$
S_{1}^{\prime}=S_{1}^{\prime \prime}=X_{1}
$$

c. Double exponential smoothing method (two parameters by Holt)

$$
\begin{gathered}
S_{1}=X_{1} \\
b_{1}=\frac{\left(X_{2}-X_{1}\right)+\left(X_{3}-X_{2}\right)}{2}
\end{gathered}
$$

\section{b. Double Exponensial Smoothing By Holt}

Exponential smoothing is a method of forecasting a moving average that assigns weight to the values of the previous period exponentially decreasing. The Double Exponential Smoothing Holt methods analyze data in a univariate manner containing trend patterns. The Double Exponential Smoothing Holt methods assume past values and errors as the basis for forecasting the future. However, each method also has advantages and disadvantages. The advantage of the Holt method is that it can model trends and levels from one time series, calculating more efficient. Double Exponential Smoothing By Holt requires less data. This method also has the flexibility of levels and trends that can be passed with different weights [12].

Doubleexponential smoothing by holt method is similar in principle to Brown's except that Holt does not use the double smoothing formula directly. Instead, Holt smooths out the trend values with different parameters from the parameters used in the original series. The forecast of Holt's linear exponential smoothing is obtained using two smoothing constants with values between 0 and $1[12]$.

The rationale for the single or multiple exponential smoothing method is the smoothing value that is found at the time before the actual data, if the data has a trend component then for single smoothing values it is necessary to add multiple smoothing values to adjust for the trend[11].This method is known as Brown's double exponential smoothing method. Holt's linear exponential smoothing method is similar in principle to Brown's except that Holt does not use the direct multiple smoothing formula. Instead, Holt smooths the trend values with different parameters from the parameters used in the original series. Holt's double exponential smoothing 
in the forecasting process performs two smooths using two parameters, $\alpha$ and $\gamma$. This method is a development of the single exponential smoothing method so that the equation become:

$$
S_{t}=\alpha X_{t}+(1-\alpha) S_{t-1}
$$

In the double exponential smoothing equation from Holt, the trend value of the previous period $\left(b_{t-1}\right)$

is directly added to the value $\left(S_{t-1}\right)$ :

$$
S_{t}=\alpha X_{t}+(1-\alpha)\left(S_{t-1}+b_{t-1}\right)
$$

As in the equations above, to get the estimated trend value using the difference between the final value and the previous one, namely $\left(S_{t}-S_{t-1}\right)$ by replacing the value of $\alpha$ with the value of $\gamma$ so that the equation becomes:

$$
B_{t}=\gamma\left(S_{t}-S_{t-1}\right)+(1-\gamma) b_{t-1}
$$

where:

$\gamma$ : value of smoothing parameter for trend estimation

$b_{t}:$ estimated trend in period $t$

So for future forecasting, the value of the trend $b_{t}$ is multiplied by the number of forward periods predicted $\mathrm{m}$ and added to the base value $S_{t}$.

where:

$$
F_{t+m}=S_{t}+b_{t+m}
$$

$F_{t+m}$ : forecasting in period to $t+m$

$S_{t} \quad$ : trend smoothing value in period $-t$

$b_{t}:$ trend factor on period $-t$

$m$ : the predicted number of periods to $m$

\section{Results and Discussion}

3.1 General Description of Covid-19 Posisitif Case In each District and City of Jambi Province Based on data obtained from http://corona.jambiprov.go.id, it is seen that positive cases of Covid-19 in Jambi Province continue to increase. From March to mid of September 2020 there were 345 positive cases of Covid-19. The following is data on positive confirmed cases of Covid-19 in each district and city in Jambi Province are

Table 1. Positive Confirmation Data for Covid-19 in Jambi Province

\begin{tabular}{cccccccc}
\hline $\begin{array}{c}\text { District/ } \\
\text { City }\end{array}$ & March & April & May & June & July & August & $\begin{array}{c}\text { September } \\
\text { *untiltgl 16 }^{\text {th }}\end{array}$ \\
\hline Sei Penuh & 0 & 1 & 13 & 19 & 21 & 26 & 26 \\
Kerinci & 1 & 1 & 1 & 1 & 4 & 7 & 12 \\
Bungo & 0 & 2 & 4 & 4 & 4 & 12 & 17 \\
Merangin & 0 & 10 & 20 & 21 & 21 & 26 & 26 \\
Tebo & 0 & 0 & 3 & 3 & 3 & 9 & 9 \\
Sarolangun & 0 & 1 & 3 & 4 & 7 & 10 & 10 \\
Batanghari & 0 & 1 & 6 & 10 & 16 & 47 & 49 \\
Tanjab & 0 & 4 & 9 & 10 & 18 & 30 & 35 \\
Barat & & & & & & & 100 \\
Jambi City & 1 & 9 & 27 & 31 & 47 & 25 & 27 \\
Muaro & 0 & 2 & 10 & 12 & 17 & & \\
\hline
\end{tabular}

http://www.eksakta.ppj.unp.ac.id/index.php/eksakta 


$\begin{array}{lccccccc}\text { Jambi } & & & & & & \\ \text { Tanjab } & 0 & 0 & 1 & 2 & 4 & 10 & 10 \\ \text { Timur } & 2 & 31 & 97 & 117 & 162 & 302 & 345 \\ \text { Jambi } & 2 & & & \end{array}$

Province

Sources: http://corona.jambiprov.go.id

\subsection{Development of Covid-19 Case in Jambi Province with Exponensial Smoothing Methode}

Double exponesial smoothing out the trend values with different parameters from the parameters used in the original series. The forecast of Holt's linear exponential smoothing is obtained using two smoothing constants with values between 0 and 1 .

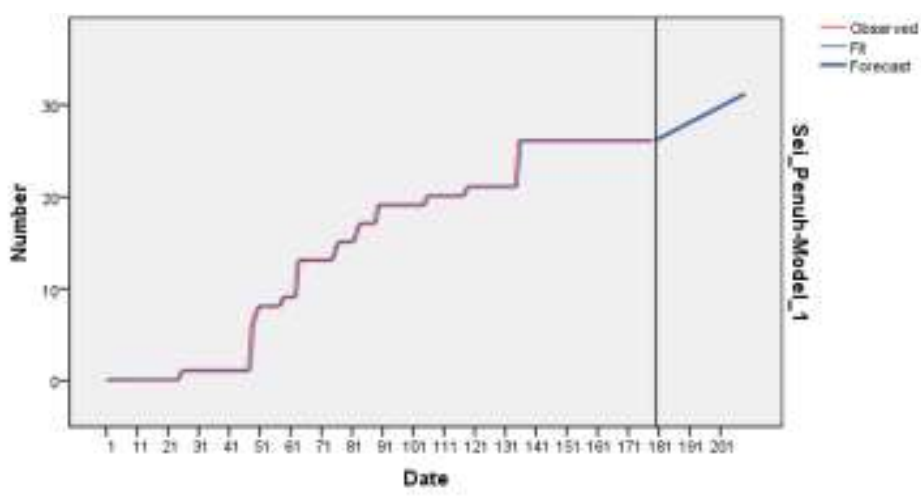

Figure 1. Prediction Positive COVID-19 case in Sei. Penuh

By using a 10 percent error rate [Figure 1], the best $\alpha$ parameter values are 1 and the best $\gamma$ is 0.001. with a Mean Absolute Percentage Error (MAPE) of 5.030 percent and MAE 0.293. In positive COVID-19 case, the MAPE dan MAE value is smaller than the error rate at $10 \%$.

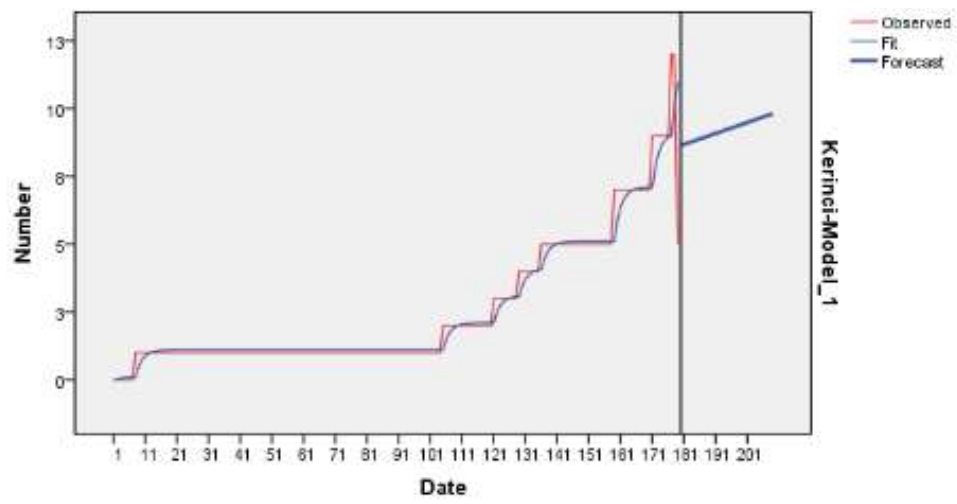

Figure 2. Prediction Positive COVID-19 case in Kerinci

By using a 10 percent error rate [Figure 2], the best $\alpha$ parameter values are 0.397 and the best $\gamma$ is0.00000014. with a Mean Absolute Percentage Error (MAPE) of 9.808percent and MAE 0.229. In positive COVID-19 case, the MAPE dan MAE value is smaller than the error rate at $10 \%$. 


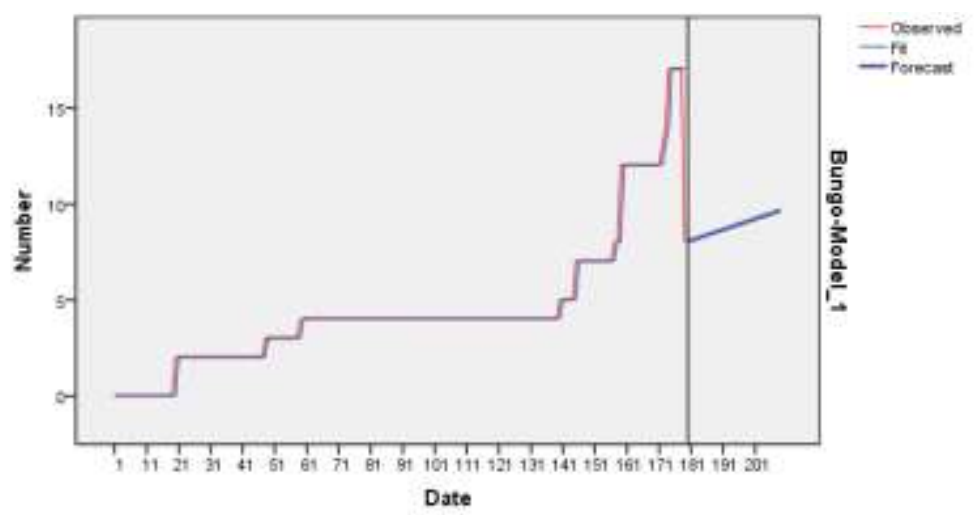

Figure 3. Prediction Positive COVID-19 case in Muaro Bungo

By using a 10 percent error rate [Figure 3], the best $\alpha$ parameter values are 1 and the best $\gamma$ is 0.001. with a Mean Absolute Percentage Error (MAPE) of 3.860 percent and MAE 0.195. In positive COVID-19 case, the MAPE dan MAE value is smaller than the error rate at $10 \%$.

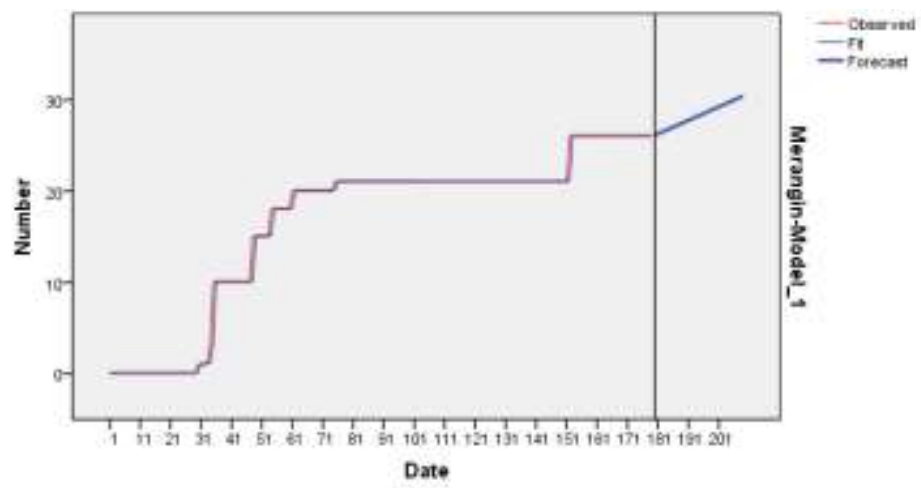

Figure 4. Prediction Positive COVID-19 case in Merangin

By using a 10 percent error rate [Figure 4] the best $\alpha$ parameter values are 1 and the best $\gamma$ is 0.001. with a Mean Absolute Percentage Error (MAPE) of 2.997 percent and MAE 0.283. In positive COVID-19 case, the MAPE dan MAE value is smaller than the error rate at $10 \%$.

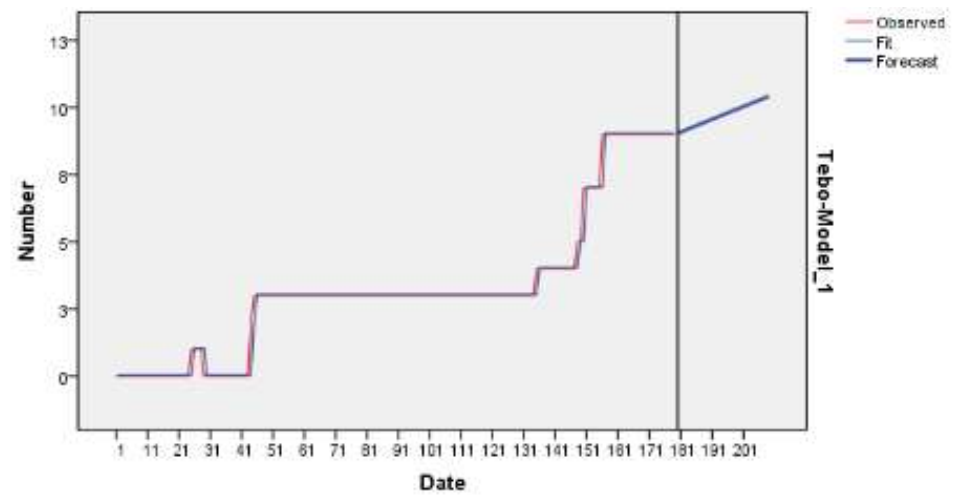

Figure 5. Prediction Positive COVID-19 case in Tebo 
By using a 10 percent error rate [Figure 5] the best $\alpha$ parameter values are 1 and the best $\gamma$ is 0.001. with a Mean Absolute Percentage Error (MAPE) of 3.553 percent and MAE 0.104. In positive COVID-19 case, the MAPE dan MAE value is smaller than the error rate at $10 \%$.

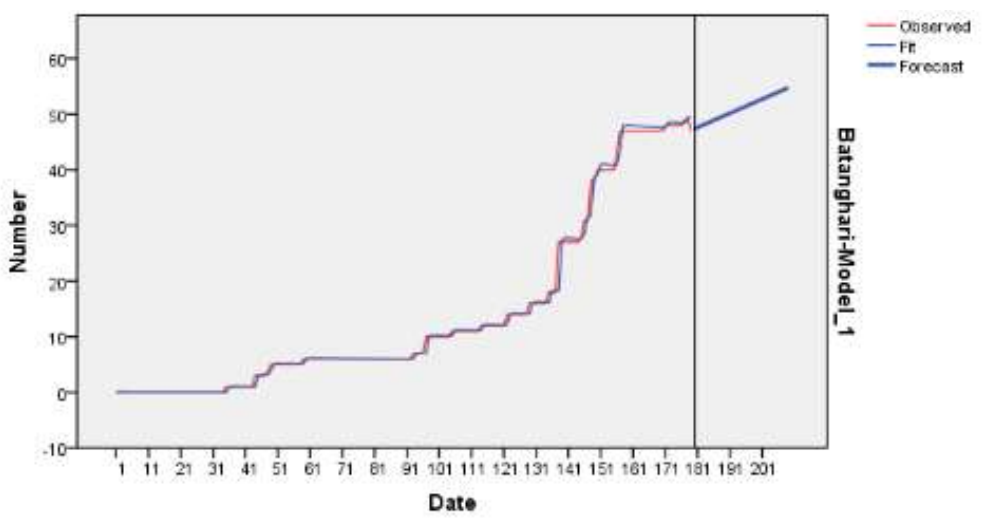

Figure 6. Prediction Positive COVID-19 case in Batanghari

By using a 10 percent error rate [Figure 6] the best $\alpha$ parameter values are 0.895 and the best $\gamma$ is 0.0000073. with a Mean Absolute Percentage Error (MAPE) of 3.877percent and MAE 0.131. In positive COVID-19 case, the MAPE dan MAE value is smaller than the error rate at $10 \%$.

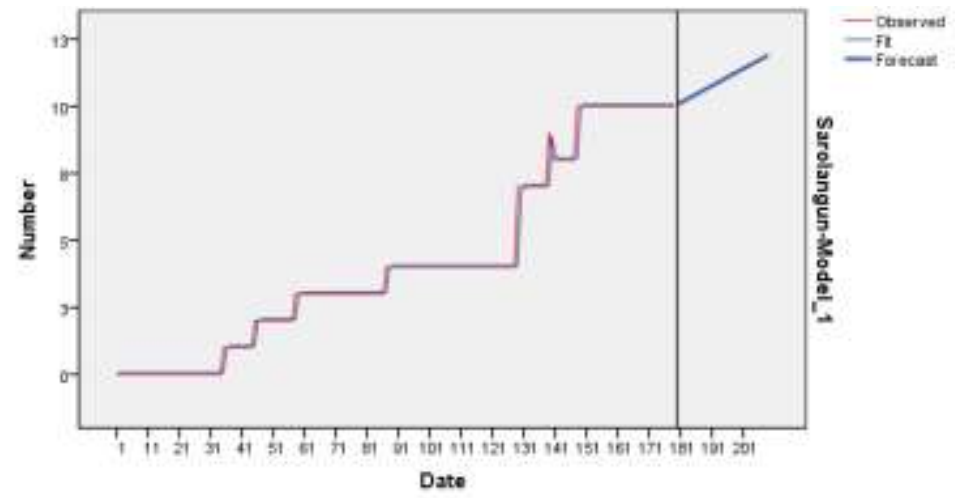

Figure 7. Prediction Positive COVID-19 case in Sarolangun

By using a 10 percent error rate [Figure 7], the best $\alpha$ parameter values are 0.95 and the best $\gamma$ is 0.06. with a Mean Absolute Percentage Error (MAPE) of 4.373 percent and MAE 0.446. In positive COVID-19 case, the MAPE dan MAE value is smaller than the error rate at $10 \%$. 


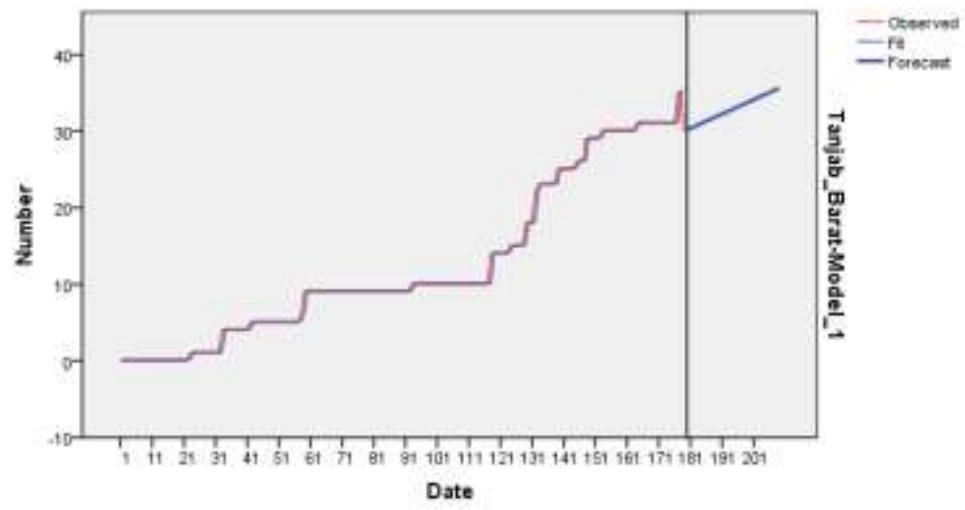

Figure 8. Prediction Positive COVID-19 case in TanjungJabung Barat

By using a 10 percent error rate [Figure 8], the best $\alpha$ parameter values are e 1 and the best $\gamma$ is 0.001. with a Mean Absolute Percentage Error (MAPE) of 4.819 percent and MAE 0.374. In positive COVID-19 case, the MAPE dan MAE value is smaller than the error rate at $10 \%$.

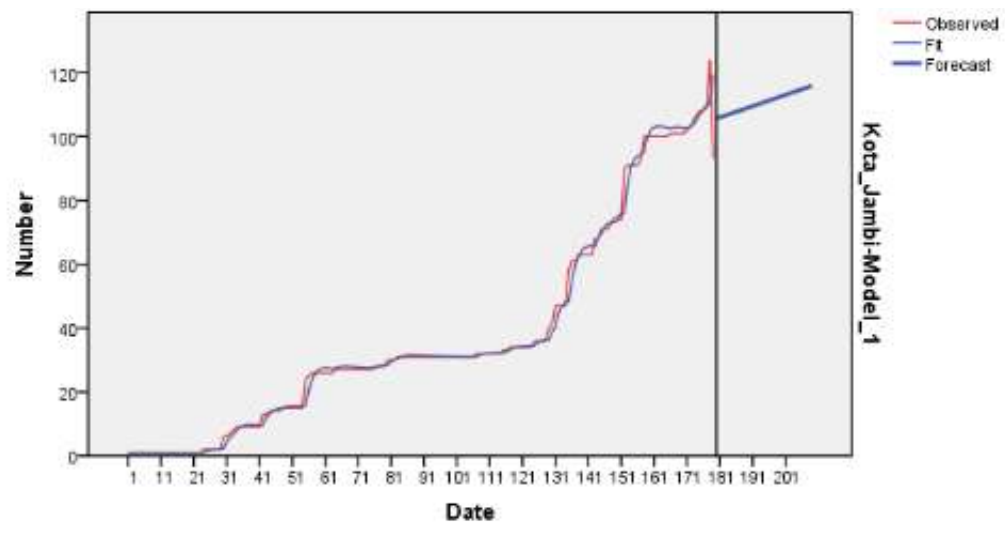

Figure 9. Prediction Positive COVID-19 case in Jambi City

By using a 10 percent error rate [Figure 9], the best $\alpha$ parameter values are 0.534 and the best $\gamma$ is 0.089 . with a Mean Absolute Percentage Error (MAPE) of 4.814 percent and MAE 1.306. In positive COVID-19 case, the MAPE dan MAE value is smaller than the error rate at $10 \%$. 


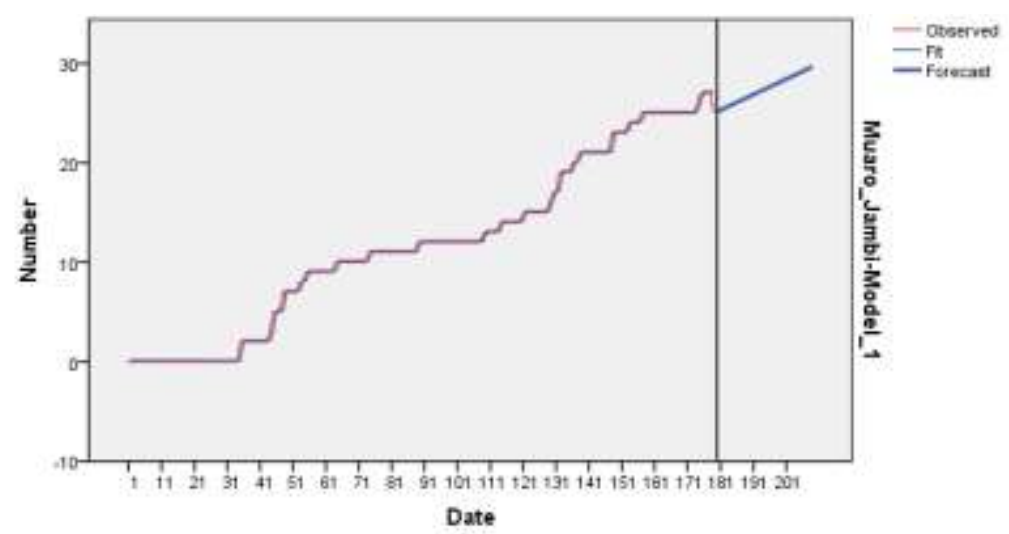

Figure 10. Prediction Positive COVID-19 case in Muaro Jambi

By using a 10 percent error rate [Figure 10], the best $\alpha$ parameter values are 1 and the best $\gamma$ is 0.001. with a Mean Absolute Percentage Error (MAPE) of 3.548 percent and MAE 0.279. In positive COVID-19 case, the MAPE dan MAE value is smaller than the error rate at $10 \%$.

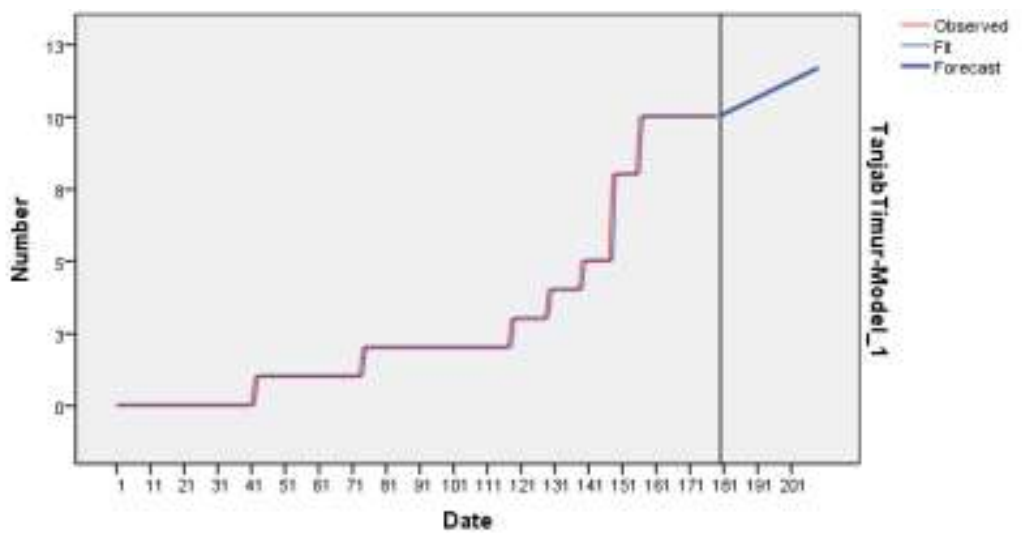

Figure 11. Prediction Positive COVID-19 case in TanjungJabung Timur

By using a 10 percent error rate [Figure 11], the best $\alpha$ parameter values are 0.994 and the best $\gamma$ is 0.0000066 . with a Mean Absolute Percentage Error (MAPE) of 4.561percent and MAE 0.108. In positive COVID-19 case, the MAPE dan MAE value is smaller than the error rate at $10 \%$.

Based on the results of forecasting using the double exponential smoothing by Holt method, it can be seen that the number of confirmed cases of Covid-19 in each region in Jambi Province continues to increase. This case is estimated to increase to 352 people in mid-October.We can see the results of forecasting using SPSS software in the following table :

Table 2. Forecasting Results Positive Covid-19 Confirmation in Jambi Province

\begin{tabular}{cccccccccccc}
\hline Forcest & $\begin{array}{c}\text { Sei. } \\
\text { Penuh }\end{array}$ & Kerinci & Bungo & Merangin & Tebo & Sarolangun & Batanghari & $\begin{array}{c}\text { Tanjab } \\
\text { Barat }\end{array}$ & $\begin{array}{c}\text { Kota } \\
\text { Jambi }\end{array}$ & $\begin{array}{c}\text { Muaro } \\
\text { Jambi }\end{array}$ & $\begin{array}{c}\text { Tanjab } \\
\text { Timur }\end{array}$ \\
\hline 1 & 26 & 9 & 8 & 26 & 9 & 10 & 47 & 30 & 106 & 25 & 10 \\
2 & 26 & 9 & 8 & 26 & 9 & 10 & 48 & 30 & 106 & 25 & 10 \\
\hline
\end{tabular}




\begin{tabular}{|c|c|c|c|c|c|c|c|c|c|c|c|}
\hline 3 & 27 & 9 & 8 & 26 & 9 & 10 & 48 & 31 & 106 & 25 & 10 \\
\hline 4 & 27 & 9 & 8 & 27 & 9 & 10 & 48 & 31 & 107 & 26 & 10 \\
\hline 5 & 27 & 9 & 8 & 27 & 9 & 10 & 48 & 31 & 107 & 26 & 10 \\
\hline 6 & 27 & 9 & 8 & 27 & 9 & 10 & 49 & 31 & 107 & 26 & 10 \\
\hline 7 & 27 & 9 & 8 & 27 & 9 & 10 & 49 & 31 & 108 & 26 & 10 \\
\hline 8 & 27 & 9 & 8 & 27 & 9 & 11 & 49 & 31 & 108 & 26 & 10 \\
\hline 9 & 28 & 9 & 9 & 27 & 9 & 11 & 49 & 32 & 108 & 26 & 11 \\
\hline 10 & 28 & 9 & 9 & 27 & 9 & 11 & 50 & 32 & 109 & 27 & 11 \\
\hline 11 & 28 & 9 & 9 & 28 & 10 & 11 & 50 & 32 & 109 & 27 & 11 \\
\hline 12 & 28 & 9 & 9 & 28 & 10 & 11 & 50 & 32 & 110 & 27 & 11 \\
\hline 13 & 28 & 9 & 9 & 28 & 10 & 11 & 50 & 32 & 110 & 27 & 11 \\
\hline 14 & 28 & 9 & 9 & 28 & 10 & 11 & 51 & 33 & 110 & 27 & 11 \\
\hline 15 & 29 & 9 & 9 & 28 & 10 & 11 & 51 & 33 & 111 & 27 & 11 \\
\hline 16 & 29 & 9 & 9 & 28 & 10 & 11 & 51 & 33 & 111 & 27 & 11 \\
\hline 17 & 29 & 9 & 9 & 29 & 10 & 11 & 51 & 33 & 111 & 28 & 11 \\
\hline 18 & 29 & 9 & 9 & 29 & 10 & 11 & 52 & 33 & 112 & 28 & 11 \\
\hline 19 & 29 & 9 & 9 & 29 & 10 & 11 & 52 & 34 & 112 & 28 & 11 \\
\hline 20 & 29 & 9 & 9 & 29 & 10 & 11 & 52 & 34 & 112 & 28 & 11 \\
\hline 21 & 30 & 9 & 9 & 29 & 10 & 11 & 52 & 34 & 113 & 28 & 11 \\
\hline 22 & 30 & 9 & 9 & 29 & 10 & 11 & 53 & 34 & 113 & 28 & 11 \\
\hline 23 & 30 & 10 & 9 & 29 & 10 & 11 & 53 & 34 & 113 & 29 & 11 \\
\hline 24 & 30 & 10 & 9 & 30 & 10 & 12 & 53 & 34 & 114 & 29 & 11 \\
\hline 25 & 30 & 10 & 9 & 30 & 10 & 12 & 53 & 35 & 114 & 29 & 11 \\
\hline 26 & 30 & 10 & 9 & 30 & 10 & 12 & 54 & 35 & 114 & 29 & 11 \\
\hline 27 & 31 & 10 & 10 & 30 & 10 & 12 & 54 & 35 & 115 & 29 & 12 \\
\hline 28 & 31 & 10 & 10 & 30 & 10 & 12 & 54 & 35 & 115 & 29 & 12 \\
\hline 29 & 31 & 10 & 10 & 30 & 10 & 12 & 54 & 35 & 116 & 30 & 12 \\
\hline 30 & 31 & 10 & 10 & 30 & 10 & 12 & 55 & 36 & 116 & 30 & 12 \\
\hline
\end{tabular}

The results of forecasting positive cases of COVID-19 in the districts and cities of Jambi province show the possibility of a significant increase in the number of cases from day to day. For this reason, it is hoped that public awareness, especially for people in Jambi Province, to comply with health protocols. In addition, the government is expected to take firm action against people who violate these health protocol rules (15-36).

\section{Conclusion}

According to the researche of forecasting the The Development of COVID-19 Case in District and City of Jambi Province with Eksponential Smoothing Methode by Holt there was an increase of 352 people in Jambi province. This data is obtained from forecasting for each district and city in Jambi province which includes Sungai penuh City the best $\alpha$ is 1 and the best $\gamma$ is 0.001 with (MAPE) of $5.030 \%$ and MAE $0.293 \%$. Kerinci the best $\alpha$ is 0.397 and the best $\gamma$ is 0.00000014 with (MAPE) of $9.808 \%$ and MAE $0.229 \%$. Muaro Bungo the best $\alpha$ is 1 and the best $\gamma$ is 0.001 with (MAPE) of $3.860 \%$ and MAE $0.195 \%$. Merangin the best $\alpha$ is 1 and the best $\gamma$ is 0.001 with MAPE of $2.997 \%$ and MAE $0.283 \%$. Tebo the best $\alpha$ is 1 and the best $\gamma$ is 0.001 with MAPE $3.553 \%$ and MAE $0.104 \%$. Batanghari the best $\alpha$ is 0.895 and the best $\gamma$ is 0.0000073 with (MAPE) $3.877 \%$ and MAE 0.131. TanjungJabung Barat the best $\alpha$ is 1 and the best $\gamma$ is 0.001 with MAPE $4.819 \%$ and MAE $0.374 \%$. Jambi city the best $\alpha$ is 0.534 and the best $\gamma$ is 0.089 with MAPE $4.814 \%$ and MAE $1.306 \%$. Muaro Jambi the best $\alpha$ is 1 and the best $\gamma$ is 0.001 with MAPE $3.548 \%$ and MAE $0.279 \%$. TanjungJabung Timur the best $\alpha$ is 0.994 and the best $\gamma$ is 0.0000066 with MAPE $4.561 \%$ 
and MAE 0.108\%. In positive COVID-19 case, the MAPE dan MAE for All city and district in Jambi Province value is smaller than the error rate at $10 \%$.

\section{References}

1. Badan Nasional PenanggulanganBencana, "JumlahKasus COVID-19 Global dan Indonesia", GugusTugasPercepatanPenanganan COVID-19. [Online]. Available: http://covid19.bnpb.go.id/. (Accessed: September 15, 2020)..

2. Alvi MM, Sivasankaran S, Singh M. (2020). Pharmacological and non-pharmacological efforts at prevention, mitigation, and treatment for COVID-19. Journal of drug targeting.28(7-8):74254.

3. Cronin AM, Railey S, Fortune D, Wegener DH, Davis JB. (2020). Notes from the Field: Effects of the COVID-19 Response on Tuberculosis Prevention and Control Efforts - United States, March-April 2020. MMWR Morbidity and mortality weekly report.69(29):971-2.

4. Peng MT. (2020). [Nurses: A Voice to Lead, Nursing the World to Health-Viewing COVID-19 Epidemic Prevention Efforts in Light of Nightingale's Perspective on Infection Control]. Hu li za zhi The journal of nursing.67(3):102-10.

5. Popescu S. (2020). Roadblocks to Infection Prevention Efforts in Healthcare SARS-CoV2/COVID-19 Response. Disaster medicine and public health preparedness.1-7.

6. Stevens MP, Doll M, Pryor R, Godbout E, Cooper K, Bearman G. (2020). Impact of COVID19 on traditional healthcare-associated infection prevention efforts. Infection control and hospital epidemiology.41(8):946-7.

7. Yen MY, Schwartz J, Chen SY, King CC, Yang GY, Hsueh PR. (2020). Interrupting COVID19 transmission by implementing enhanced traffic control bundling: Implications for global prevention and control efforts. Journal of microbiology, immunology, and infection $=$ Wei mian yu gan ran za zhi.53(3):377-80.

8. Harini, Siti. 2020. Identification COVID-19 Cases in Indonesia with The Double Exponential Smoothing Method, JurnalMatematika MANTIK, 6, 66-75.

9. Jambi Siaga COVID-19, "Data Statistik COVID-19 Provinsi Jambi", PemerintahProvinsi Jambi. [Online]. Available: http://corona.jambiprov.go.id. (Accessed: September 15, 2020)

10. Pindyck, Robert S., and Rubinfeld, Daniel L. (1998). Econometrics Models and Economic Forcest, \$th.Singapore : Mc Graw Hill.

11. S. Makridakis. (2003). Metode dan AplikasiPeramalanJilid 1 (EdisiRevisi). Jakarta: BinarupaAksara.

12. Worldometer, "Covid-19 Corona virus Pandemic", worldometer, 2020. [Online],Available: https://www.worldometers.info/coronavirus/country/indonesia/,(Accessed: September 10, 2020).

13. World Health Organization. Coronavirus disease (COVID-19) advice for the public [Online]. 2020.Available from: https://www.who.int/emergencies/diseases/ novel-coronavirus2019/advice-for-public. (Accessed: September 15, 2020).

14. World Health Organization. Coronavirus disease (COVID-19) advice for the public [Online]. Available from: https://www.who.int/emergencies/diseases/ novel-coronavirus-2019/advicefor-public. (Accessed: September 15, 2020).

15. Alharbi A, Alharbi S, Alqaidi S. (2020). Guidelines for dental care provision during the COVID-19 pandemic. The Saudi dental journal.32(4):181-6.

16. Ather A, Patel B, Ruparel NB, Diogenes A, Hargreaves KM. (2020). Coronavirus Disease 19 (COVID-19): Implications for Clinical Dental Care. Journal of endodontics.46(5):584-95. 
17. Calvo C, Garcia Lopez-Hortelano M, de Carlos Vicente JC, Vazquez Martinez JL, Grupo de trabajo de la Asociacion Espanola de Pediatria para el brote de infeccion por Coronavirus cceMdS, Miembros del Grupo de Expertos de la AEP. (2020). [Recommendations on the clinical management of the COVID-19 infection by the $<<$ new coronavirus $>>$ SARS-CoV2. Spanish Paediatric Association working group]. Anales de pediatria.92(4):241 e1- e11.

18. Chen W, Su XY, Wang VJ, Wang EC, Xu R, Zhong S, et al. (2020). Novel Coronavirus International Public Health Emergency: Guidance on Radiation Oncology Facility Operation. Advances in radiation oncology.5(4):560-6.

19. Chisci E, Masciello F, Michelagnoli S. (2020). The Italian USL Toscana Centro model of a vascular hub responding to the COVID-19 emergency. Journal of vascular surgery.72(1):8-11.

20. de Lusignan S, Lopez Bernal J, Zambon M, Akinyemi O, Amirthalingam G, Andrews N, et al. (2020). Emergence of a Novel Coronavirus (COVID-19): Protocol for Extending Surveillance Used by the Royal College of General Practitioners Research and Surveillance Centre and Public Health England. JMIR public health and surveillance.6(2):e18606.

21. Escalera-Antezana JP, Lizon-Ferrufino NF, Maldonado-Alanoca A, Alarcon-De-la-Vega G, Alvarado-Arnez LE, Balderrama-Saavedra MA, et al. (2020). Clinical features of the first cases and a cluster of Coronavirus Disease 2019 (COVID-19) in Bolivia imported from Italy and Spain. Travel medicine and infectious disease.35:101653.

22. Foddai A, Lubroth J, Ellis-Iversen J. (2020). Base protocol for real time active random surveillance of coronavirus disease (COVID-19) - Adapting veterinary methodology to public health. One health.9:100129.

23. Glauser W. (2020). Proposed protocol to keep COVID-19 out of hospitals. CMAJ : Canadian Medical Association journal = journal de l'Association medicale canadienne.192(10):E264-E5.

24. Gonzalez-Brown VM, Reno J, Lortz H, Fiorini K, Costantine MM. (2020). Operating Room Guide for Confirmed or Suspected COVID-19 Pregnant Patients Requiring Cesarean Delivery. American journal of perinatology.37(8):825-8.

25. Hsieh TY, Dedhia RD, Chiao W, Dresner H, Barta RJ, Lyford-Pike S, et al. (2020). A Guide to Facial Trauma Triage and Precautions in the COVID-19 Pandemic. Facial plastic surgery \& aesthetic medicine.22(3):164-9.

26. Li W, Zhou Q, Tang Y, Ren L, Yu X, Li Q, et al. (2020). Protocol for the development of a rapid advice guidelines for management of children with SARS-CoV-2 infection. Annals of palliative medicine.9(4):2251-5.

27. Li Y, Liu X, Guo L, Li J, Zhong D, Zhang Y, et al. (2020). Traditional Chinese herbal medicine for treating novel coronavirus (COVID-19) pneumonia: protocol for a systematic review and meta-analysis. Systematic reviews.9(1):75.

28. Liu S, Zheng Q, Wang Z. (2020). Potential covalent drugs targeting the main protease of the SARS-CoV-2 coronavirus. Bioinformatics.36(11):3295-8.

29. Nicastri E, D'Abramo A, Faggioni G, De Santis R, Mariano A, Lepore L, et al. (2020). Coronavirus disease (COVID-19) in a paucisymptomatic patient: epidemiological and clinical challenge in settings with limited community transmission, Italy, February 2020. Euro surveillance : bulletin Europeen sur les maladies transmissibles $=$ European communicable disease bulletin.25(11).

30. O'Reilly GM, Mitchell RD, Noonan MP, Hiller R, Mitra B, Brichko L, et al. (2020). Informing emergency care for COVID-19 patients: The COVID-19 Emergency Department Quality Improvement Project protocol. Emergency medicine Australasia : EMA.32(3):511-4. 
31. Padoan A, Cosma C, Sciacovelli L, Faggian D, Plebani M. (2020). Analytical performances of a chemiluminescence immunoassay for SARS-CoV-2 IgM/IgG and antibody kinetics. Clinical chemistry and laboratory medicine.58(7):1081-8.

32. Qin YY, Zhou YH, Lu YQ, Sun F, Yang S, Harypursat V, et al. (2020). Effectiveness of glucocorticoid therapy in patients with severe coronavirus disease 2019: protocol of a randomized controlled trial. Chinese medical journal.133(9):1080-6.

33. Sulmasy DP, Veatch RM. (2020). Should Institutions Disclose the Names of Employees with Covid-19? The Hastings Center report.50(3):25-7.

34. Tang HS, Yao ZQ, Wang WM. (2020). [Emergency management of prevention and control of the novel coronavirus infection in departments of stomatology]. Zhonghua kou qiang yi xue za zhi $=$ Zhonghua kouqiang yixue zazhi $=$ Chinese journal of stomatology.55(4):246-8.

35. Wang H, Jin XY, Pang B, Liu CX, Zheng WK, Yang FW, et al. (2020). [Analysis on clinical study protocols of traditional Chinese medicine for coronavirus disease 2019]. Zhongguo Zhong yao za zhi $=$ Zhongguo zhongyao zazhi $=$ China journal of Chinese materia medica.45(6):1232-41.

36. Xiao WJ, Gao Q, Jin K, Gong XH, Han RB, Jiang CY, et al. (2020). [Investigation of an epidemic cluster caused by COVID rectangle19 cases in incubation period in Shanghai]. Zhonghua liu xing bing xue za zhi = Zhonghua liuxingbingxue zazhi.41(0):E033. 